\title{
Prescribing Patterns of Onychomycosis Therapies in the United States
}

\author{
Eric J. Yang, MD; Shari R. Lipner, MD, PhD
}

\section{PRACTICE POINTS}

- Dermatologists should consider efficacy and cost of onychomycosis therapies, as inappropriate treatment selection results in longer treatment courses and increased costs.

- Creation of consensus guidelines for the management of onychomycosis may decrease the costs of treating this difficult-to-manage disease.

To the Editor:

Onychomycosis is the most common nail disorder, affecting approximately $5.5 \%$ of the world's population. ${ }^{1}$ There are a limited number of topical and systemic therapies approved by the US Food and Drug Administration (FDA), but no consensus guidelines exist for the management of onychomycosis. Therefore, we hypothesized that prescribing patterns would vary among different groups.

We examined data from the Centers for Medicare \& Medicaid Services' Part D Prescriber Public Use Files for 2013 to 2016. ${ }^{2}$ Prescribing patterns were assessed for dermatologists, nurse practitioners, physician assistants, and podiatrists prescribing systemic (ie, terbinafine, itraconazole) or topical (ie, efinaconazole, tavaborole, ciclopirox) therapies. A cut-off of systemic therapy lasting 84 days or more (reflecting FDA-approved treatment regimens for toenail onychomycosis) was used to exclude prescriptions for other fungal conditions that require shorter treatment courses. Statistical analysis with $\chi^{2}$ tests identified differences among specialties' prescribing patterns.

Overall, onychomycosis medications accounted for \$85.4 million in expenditures from 2013 to 2016, with spending increasing at a rate of $21.2 \%$ annually (Table 1 ). The greatest single-year increase was observed from 2014 to 2015, with a $40.6 \%$ surge in overall expenditures for onychomycosis medications-increasing from $\$ 17.8$ million to $\$ 25.0$ million in spending. Dermatologists' prescriptions accounted for $14.8 \%$ of all claims for onychomycosis medications and $18.3 \%$ of total expenditures during the study period, totaling $\$ 15.7$ million in costs. Dermatologists' claims increased at a rate of $7.4 \%$ annually, while expenditures increased at $15.4 \%$ annually. A greater proportion of dermatologists (96.4\%) prescribed topicals for onychomycosis relative to nurse practitioners $(90.2 \%)$ and podiatrists $(91.3 \%)(P<.01)$ (Table 2$)$. No significant difference was observed in the prescribing patterns of dermatologists and physician assistants $(P=.99)$.

Per-claim spending for treating onychomycosis increased $7.4 \%$ annually for dermatologists, second only to podiatrists at $17.2 \%$ annually. Each analyzed group reported at least a $7 \%$ annual increase in the amount of topicals prescribed for onychomycosis. Following their FDA approvals in 2014,

\section{TABLE 1. Annual Medicare Expenditures by Specialty on Onychomycosis Medications,} 2013-2016

\begin{tabular}{|c|c|c|c|c|c|}
\hline \multirow[b]{2}{*}{ Specialty } & \multicolumn{4}{|c|}{ Medicare Expenditures, \$ } & \multirow{2}{*}{$\begin{array}{l}\text { Average Annual } \\
\text { Increase, \% }\end{array}$} \\
\hline & 2013 & 2014 & 2015 & 2016 & \\
\hline Dermatology & $3,004,252$ & $3,338,692$ & $4,704,022$ & $4,613,263$ & 15.4 \\
\hline Nurse practitioner & 320,026 & 429,881 & 618,487 & 921,720 & 42.3 \\
\hline Physician assistant & 463,653 & 623,622 & 708,046 & 926,380 & 26.0 \\
\hline Podiatry & $6,724,957$ & $7,991,573$ & $12,576,977$ & $14,509,495$ & 29.2 \\
\hline Total & $15,326,133$ & $17,762,015$ & $24,977,368$ & $27,293,034$ & 21.2 \\
\hline
\end{tabular}

Dr. Yang is from Department of Dermatology, Warren Alpert Medical School, Brown University, Providence, Rhode Island. Dr. Lipner is from the Department of Dermatology, Weill Cornell Medicine, New York, New York.

The authors report no conflict of interest.

Correspondence: Eric J. Yang, MD, 593 Eddy St, Providence, RI 02903 (ericjyang@outlook.com).

doi:10.12788/cutis.0132 
TABLE 2. Total Number of Prescribers for Onychomycosis Treatments, 2013-2016

\begin{tabular}{lllll}
\hline Medication & Dermatology, $\mathbf{n}(\%)$ & Podiatry, $\mathbf{n}(\%)$ & Physician Assistant, $\mathbf{n}(\%)$ & Nurse Practitioner, $\mathbf{n}(\%)$ \\
\hline $\begin{array}{l}\text { Systemics } \\
\text { Terbinafine }\end{array}$ & $295(5)$ & $1406(11)$ & $67(5)$ & $69(8)$ \\
\hline $\begin{array}{l}\text { Itraconazole } \\
\text { Topicals }\end{array}$ & $0(0)$ & $8(0)$ & $2(0)$ & $21(2)$ \\
Ciclopirox & $5893(93)$ & $11,183(88)$ & $1377(94)$ & $752(88)$ \\
\hline Efinaconazole & $275(4)$ & $561(4)$ & $23(2)$ & $16(2)$ \\
\hline Tavaborole & $49(1)$ & $208(2)$ & $14(1)$ & $2(0)$ \\
Total & 6330 & 12,682 & 1466 & 853 \\
\hline
\end{tabular}

tavaborole and efinaconazole accounted for $0.9 \%$ and $2.3 \%$ of onychomycosis claims in 2016, respectively, and $15.0 \%$ and $25.1 \%$ of total Medicare expenditures on onychomycosis treatments that same year, respectively. Itraconazole also disproportionately contributed to expenditures, accounting for $1.3 \%$ of onychomycosis claims in 2016 while accounting for $9.5 \%$ of total expenditures.

The introduction of efinaconazole and tavaborole in 2014 resulted in large increases in Medicare spending for onychomycosis. Limited manufacturer competition due to patents may contribute to increased spending on these topicals in the future. ${ }^{3}$ A prior analysis demonstrated that podiatrists prescribe topicals more often than other clinicians, ${ }^{4}$ but after adjusting for the number of dermatologists managing onychomycosis, we found that a greater proportion of dermatologists (96.4\%) are prescribing topicals for onychomycosis than other clinicians. This includes these newly approved, high-cost topicals, thus disproportionately contributing to the cost burden of onychomycosis treatment.

Ciclopirox is the most commonly prescribed therapy for onychomycosis across all groups, prescribed by more than $88 \%$ of prescribers in all studied specialties. Although ciclopirox is one of the least expensive treatment options available for onychomycosis, it has the lowest relative cure rate..$^{5}$ Onychomycosis management requires understanding of drug efficacy and disease severity. ${ }^{6}$ Inappropriate treatment selection may result in prolonged treatment courses and increased costs. Consensus guidelines for onychomycosis therapies across specialties may yield more cost-effective treatment for this common nail condition.

Acknowledgment-The authors thank Paul J. Christos, DrPH, MS (New York, New York), for his advisement regarding statistical analysis for this manuscript.

\section{REFERENCES}

1. Lipner SR, Scher RK. Onychomycosis: clinical overview and diagnosis. J Am Acad Dermatol. 2019;80:835-851.

2. Medicare provider utilization and payment data: part D prescriber. Centers for Medicare \& Medicaid Services website. https://www. cms.gov/Research-Statistics-Data-and-Systems/Statistics-Trends -and-Reports/Medicare-Provider-Charge-Data/Part-D-Prescriber. Updated November 27, 2019. Accessed November 22, 2020.

3. Yang EJ, Lipner SR. Pharmacy costs of medications for the treatment of onychomycosis in the United States. J Am Acad Dermatol. 2019;81:276-278.

4. Singh P, Silverberg JI. Trends in utilization and expenditure for onychomycosis treatments in the United States in 2013-2016. Am J Clin Dermatol. 2019;20:311-313.

5. Lipner SR, Scher RK. Onychomycosis: treatment and prevention of recurrence. J Am Acad Dermatol. 2019;80:853-867.

6. Lipner SR. Pharmacotherapy for onychomycosis: new and emerging treatments. Expert Opin Pharmacother. 2019;20:725-735. 